\title{
Abordaje sistemático para traqueostomía en pacientes con COVID-19 por el Servicio de Cirugía Maxilofacial del Centro Médico «Lic. Adolfo López Mateos»: propuesta de protocolo y revisión de la literatura
}

\author{
Systematic approach for tracheostomy in patients with COVID-19 by \\ the Maxillofacial Surgery Service of the «Lic. Adolfo López Mateos» \\ Medical Center: protocol proposal and literature review
}

\author{
Erick Geovanny Reyes Castañeda,* José Edgar Garduño Mejía, \\ Jorge Andrés Díaz Moreno, ${ }^{\S}$ José Irving Soto Orozco" ${ }^{\mathbb{I}}$
}

\section{RESUMEN}

A finales de 2019 aparecieron casos de neumonía asociada con una cepa nueva y altamente contagiosa de coronavirus denominado COVID-19 (SARS-CoV-2) que inició en un mercado en Wuhan, China. El 30 de enero de 2020, la Organización Mundial de la Salud (OMS) declaró el COVID-19 como la sexta emergencia de salud pública de preocupación internacional. En la actualidad, la epidemia de 2019-nCoV está cruzando un periodo crítico con más de 8,242,999 contagios. El análisis del SARS-CoV-2 ha reconocido a éste como causante de síntomas respi-

\section{ABSTRACT}

In late 2019, cases of pneumonia associated with a new, highly contagious strain of coronavirus called COVID-19 (SARS-CoV-2) appeared, starting in a market in Wuhan, China. On January 30, 2020, the World Health Organization (WHO) declared COVID-19 the sixth public health emergency of international concern. Currently, the 2019-nCoV epidemic is crossing a critical period with more than 8,242,999 people infected. Testing for SARSCoV-2 has been well recognized as causing mild to severe respiratory symptoms secondary to viral pneumonia

\section{* Médico adscrito. \\ ‡ Jefe de Servicio. \\ $\S$ Residente de primer año de Cirugía Maxilofacial. \\ "Residente de tercer año de Cirugía Maxilofacial. \\ Centro Médico «Lic. Adolfo López Mateos». Toluca de Lerdo, Estado de México.


ratorios similares secundarios a una neumonía viral, que van de leves a graves y en algunos casos la progresión al síndrome de dificultad respiratoria aguda (SDRA). En relación con la manifestación clínica, aproximadamente $5 \%$ de las personas infectadas tienen un curso crítico que amerita ingreso a la unidad de terapia intensiva (UTI o unidad de cuidados intensivos [UCI]) y apoyo mecánico ventilatorio. Esta población es apta a la realización de traqueostomía. Objetivo: Establecer un protocolo por parte del Servicio de Cirugía Maxilofacial del Centro Médico «Lic. Adolfo López Mateos» para la realización de traqueostomía en pacientes con COVID-19 dentro de la República Mexicana. Resultados: Se identificaron cuatro pacientes con COVID-19, tres hombres y una mujer, de los cuales todos presentaban síndrome de dificultad respiratoria aguda con apoyo de ventilación mecánica a quienes se les realiza la traqueostomía debido a la necesidad de intubación prolongada en un periodo de mayo a junio de 2020.

Palabras clave: Traqueostomía, COVID-19, SARSCoV-2, cirugía oral y maxilofacial. and in some cases progression to acute respiratory distress syndrome (ARDS). In relation to the clinical manifestation, approximately $5 \%$ of the infected persons have a critical course, which deserves admission to the Intensive Care Unit (ICU) and mechanical ventilatory support, this population is suitable for tracheotomy. Objective: To establish a protocol made by the service of maxillofacial surgery of the Medical Center «Lic. Adolfo López Mateos» for the accomplishment of tracheostomy in patients with COVID-19 within the Mexican Republic. Results: Four patients with COVID-19 were identified, of whom three were men and one was woman, all of whom presented acute respiratory distress syndrome with mechanical ventilation support. These patients underwent tracheostomy due to the need for prolonged intubation in a period from May to June 2020.

Keywords: Tracheostomy, COVID-19, SARS-CoV-2, oral and maxillofacial surgery.

\section{INTRODUCCIÓN}

En diciembre de 2019 aparecieron casos de neumonía sin explicación aparente en Wuhan, China. Tiempo después se confirmó que era un tipo de neumonía causada por una nueva infección viral, el nuevo coronavirus 2019 (COVID-19) que se ha asociado con la cepa novedosa altamente contagiosa de coronavirus (SARS-CoV-2). El 30 de enero de 2020, la Organización Mundial de la Salud (OMS) declaró COVID-19 como la sexta emergencia de salud pública de preocupación internacional. En la actualidad, la epidemia de 2019-nCoV está cruzando un periodo crítico con más de 8,844,171 contagios y más de 465,460 muertes a nivel global a la fecha del 21 de junio de 2020. . $^{-4}$

Desde que se dio a conocer el brote de COVID2019, en México se establecieron medidas de control siendo una de las iniciales a partir del 09 de enero de 2020. La Dirección General de Epidemiología emitió un aviso preventivo de viajes a China, y posteriormente se publicó el lineamiento estandarizado para la vigilancia epidemiológica y por laboratorio de enfermedad por nCoV-2019, en el que se establecieron las definiciones operacionales. ${ }^{5}$

Siguiendo el cronograma epidemiológico de nuestro país, el día 28 de febrero de 2020 se anunció el primer caso confirmado a través del InDRE, se trató de un paciente que acudió a consulta al Instituto Nacional de Enfermedades Respiratorias (INER), tenía el antecedente de haber viajado a Bérgamo,
Italia, donde estuvo en contacto con un individuo infectado. Al 21 de junio de 2020 se han confirmado 180,545 casos y 21,825 defunciones por COVID-19 en la República Mexicana, en el Estado de México se reportan 28,505 casos confirmados y 3,092 defunciones. ${ }^{5}$

El Centro Médico «Lic. Adolfo López Mateos» perteneciente al Instituto de Salud para el Bienestar (INSABI) es de atención pública, concentró pacientes de todo el Estado de México y estados vecinos, al día 19 de junio de 2020 se han recibido 1,072 pacientes de COVID-19, de los cuales se reportan 376 confirmados por parte de servicio de epidemiología.

El análisis del SARS-CoV-2 ha reconocido a éste como causante de síntomas respiratorios similares secundarios a una neumonía viral, que van de leves a graves y en algunos casos la progresión al síndrome de dificultad respiratoria aguda (SDRA). Las apariencias radiológicas típicas son la opacificación y consolidación de apariencia de vidrio deslustrado que pueden afectar múltiples lóbulos y progresar hacia la consolidación difusa y densa (Figura 1). ${ }^{6}$

La importancia de este virus se debe a su alta virulencia, ya sea adquirido por contacto o proximidad con la persona infectada o a través del contacto con los medios en los que el agente infeccioso puede sobrevivir como el medio ambiente. ${ }^{7}$

En relación con la manifestación clínica, aproximadamente $5 \%$ de las personas infectadas tienen un curso crítico, que amerita ingreso a la unidad de terapia intensiva (UTI o unidad de cuidados 
intensivos [UCI]) y apoyo mecánico ventilatorio, esta población es apta a la realización de traqueotomía. ${ }^{7}$

La traqueostomía es un procedimiento que se realiza por varias especialidades: cirugía general, neurocirugía, cirugía maxilofacial y otorrinolaringología. En la cirugía maxilofacial, las indicaciones para la traqueotomía incluyen afecciones y operaciones del sistema aerodigestivo superior correlacionadas con síntomas disneicos: enfermedad inflamatoria, enfermedad neoplásica y trauma, donde el paciente tiene que estar bajo control o necesitar ventilación mecánica después de la operación.

En el Centro Médico «Lic. Adolfo López Mateos» del INSABI el servicio de cirugía maxilofacial realiza las traqueostomías que nuestros pacientes llegan a requerir de acuerdo con las indicaciones ya antes mencionadas, también participa de manera rutinaria con los servicios de neurocirugía, medicina interna y unidad de cuidados intensivos, se nos interconsulta para realizar traqueotomías de pacientes que han
Día 1
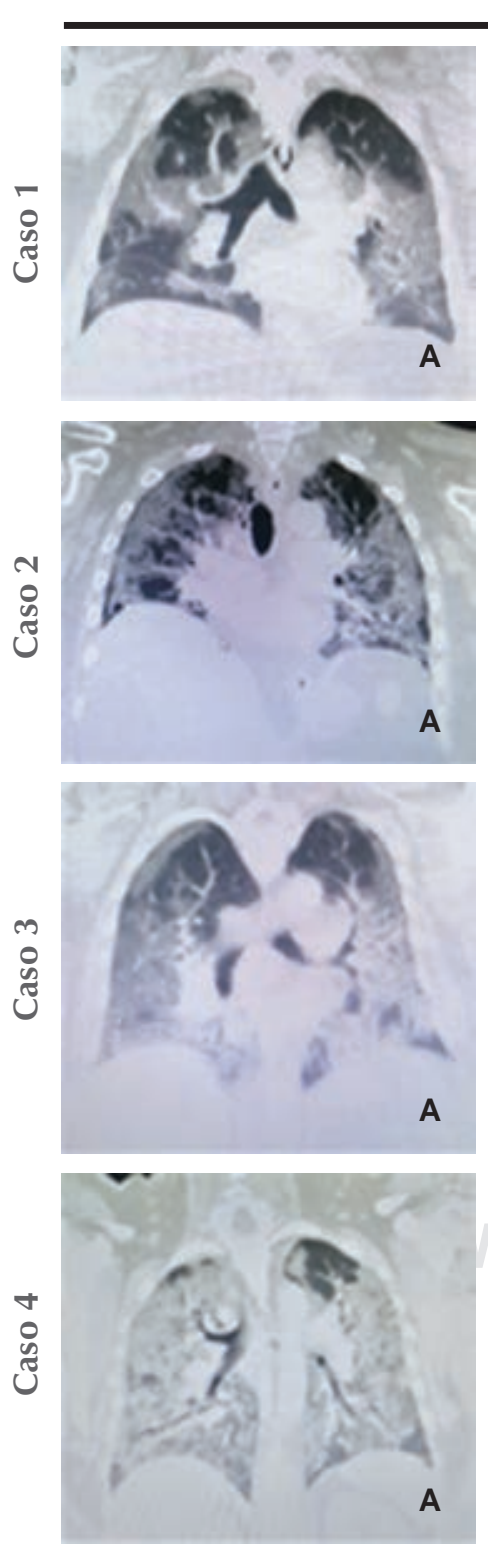

Día 14-21
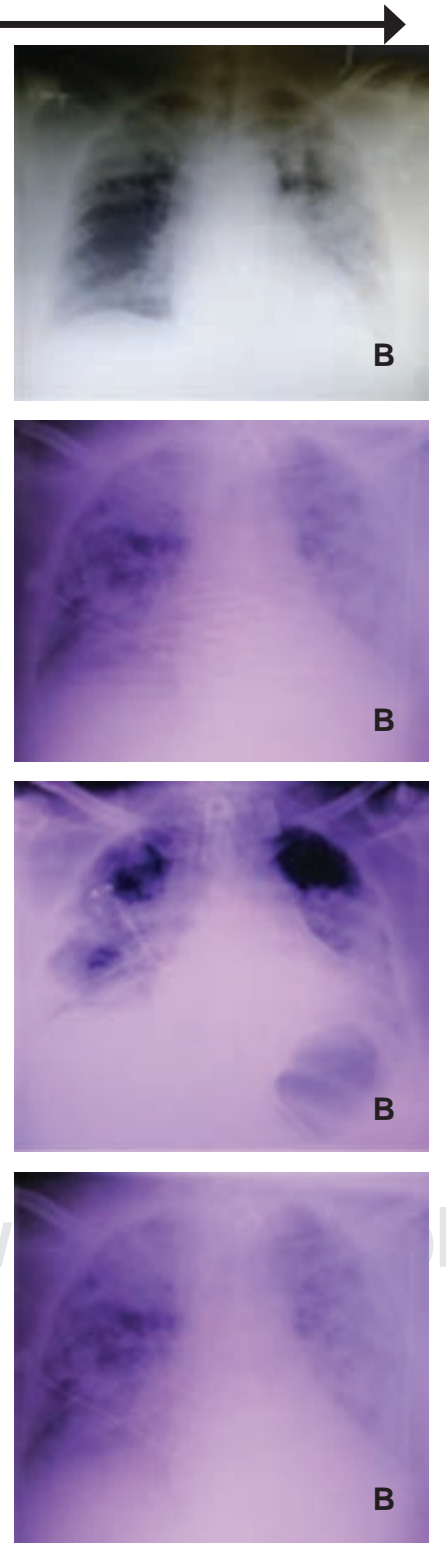

Femenino de 49 años de edad, 88 kg, sin antecedentes crónico degenerativos, inicia sintomatología (odinofagia y malestar general) tres días previos a su ingreso, saturación de $50 \%$, con datos tomográficos (A) de infiltrado pulmonar con apariencia similar a vidrio deslustrado. Se realiza intubación a su ingreso y se mantiene durante 21 días hasta que se realiza traqueostomía por nuestro servicio.

Masculino de 80 años, 66 kg, antecedentes de diabetes mellitus tipo 2, hipertensión arterial y EPOC, sintomatología inicial es en base a cefaleas, mialgias y artralgias de manera súbita con alzas térmicas no cuantificadas a su ingreso con datos de disnea y saturación de 70\%, tomografía de ingreso con infiltrados bilaterales (A) evolución hasta día 21 (B) cuando se realiza traqueostomía.

Masculino de 31 años, 85 kg, sin antecedentes crónico degenerativos, inicia con disnea en forma súbita, tos productiva, al ingreso cuenta datos de saturación de oxígeno de $56 \%$, a la valoración tomográfica presenta infiltrado pulmonar desde las bases hasta los ápices así como áreas de consolidación y broncograma aéreo bilateral (A) 21 días subsecuentes al ingreso realiza la traqueostomía, sin complicaciones reportadas.

Masculino de 52 años, 73 kg, sin antecedentes crónico degenerativos, sintomatología inicial a base de adinamia, astenia, mialgias y artralgias de manera súbita con fiebre, con tos productiva, ingresa con seis días de evolución, se presenta con datos severos de disnea, saturación de oxígeno reportada de 38\%, tomografía con subpleurales bilaterales en empedrado, (A) secuencia de intubación rápida a su ingreso, traqueostomía se realiza en día 21, en imagen B postquirúrgica con buena posición de cánula traqueal.

Figura 1: Estudios de gabinete de pacientes con diagnóstico de COVID-19 a quienes se realizó traqueostomías por el Servicio de Cirugía Maxilofacial en el Centro Médico «Lic. Adolfo López Mateos». 
tenido intubación prolongada debido a distintas afecciones relacionadas con las especialidades interconsultantes. Es por ello que debido a la pandemia seguimos participando de manera activa en la realización de traqueostomías en pacientes con diagnóstico positivo de COVID-19 que han estado con intubaciones prolongadas, de tal manera nos vimos en la necesidad de modificar nuestros protocolos previamente establecidos con las precauciones que esta enfermedad requiere.

Para entender la conducta ante el paciente enfermo de COVID-19 que requiere traqueostomía, se tienen que considerar las características de las partículas potencialmente infectantes para el personal de salud. Estas partículas, divididas por su tamaño, son las gotas y los aerosoles. Las gotas son partículas mayores de $0.1 \mathrm{~mm}$ que se expulsan al hablar, exhalar, toser o estornudar (sin cubrirse nariz y boca) hasta una distancia de 6 metros, y que quedan depositadas en las superficies que, dependiendo del material, el virus sobrevive diferentes periodos. Estas gotas infectantes en una persona se depositan en la cavidad nasal, la nasofaringe y la orofaringe, principalmente. Los aerosoles son partículas que miden menos de 10 micras que al ser tan livianas quedan suspendidas en el medio ambiente, son capaces de desplazarse a grandes distancias y al ser inhaladas se alojan hasta nivel alveolar. $^{8}$

Los procedimientos con riesgo de aerosolización no necesariamente involucran flujo aéreo, por ello para que un procedimiento genere aerosoles requiere que ocurra un evento que los genere. Estos procedimientos son la laringoscopia previa a la intubación, la intubación en sí, la aspiración traqueal y las traqueostomías. La traqueotomía generará aerosoles si se precipita un evento de tos o si se aspira durante el proceso o si se aplica ventilación con presión positiva concurrente. Los eventos generadores de aerosoles pueden prevenirse con adecuado bloqueo neuromuscular para evitar la precipitación de tos, siguiendo las recomendaciones y realizado de manera adecuada el procedimiento. 7

En una unidad de cuidados intensivos típica, la traqueostomía se indica para pacientes con ventilación crítica, por lo general se hace de manera temprana antes de cumplir 10 días, y presenta los siguientes beneficios:

- Aumenta la liberalización del ventilador y reduce el tiempo de ventilación mecánica en un promedio de 8.5 días.
- Reduce la estancia en la UCI.

- Se asocia a reducción de mortalidad.

- Disminuye el riesgo de desarrollar estenosis subglótica.

- Disminuye el uso de sedación..$^{9-11}$

La traqueostomía se puede considerar en pacientes con COVID-19 con periodos prolongados de intubación, más de 21 días; sin embargo, ésta no se debería considerar de forma rutinaria en un periodo menor que el mencionado únicamente por dependencia prolongada del ventilador, dado el alto riesgo de transmisión y el mal pronóstico de los pacientes que requieren intubación y ventilación en la literatura existente. ${ }^{11-13}$ Las guías del 27 de marzo de 2020 de la Academia Americana de Otorrinolaringología establecen que a no ser que se trate de una emergencia, a todos los pacientes que requieran un procedimiento quirúrgico se deberá hacer prueba para COVID-19 por lo menos 48 horas antes. ${ }^{13}$

En la actualidad se han publicado múltiples protocolos ${ }^{6,7,9,14-16}$ para disminuir o anular la transmisión intraoperatoria de SARS-CoV-2 durante una traqueostomía que diversos organismos han establecido. Presentamos el protocolo que utilizamos en pacientes con COVID-19 para realizar la traqueostomía en nuestro centro médico y su posible aplicación en las distintas dependencias de salud de la República Mexicana, inclusive como referencia a nivel internacional.

El objetivo de este artículo es establecer un protocolo realizado por el Servicio de Cirugía Maxilofacial del Centro Médico «Lic. Adolfo López Mateos» para traqueostomía en pacientes con COVID-19 dentro de la República Mexicana. Comparar protocolos propuestos en la literatura para la ejecución de la traqueostomía, eficacia del equipo de protección del personal de salud y en la técnica de colocación.

\section{MATERIAL Y MÉTODOS}

\section{Protocolo para realizar traqueostomía en pacientes con COVID-19}

Equipo necesario de acuerdo al personal y funciones:

Se debe reducir el número de personal dentro de la sala quirúrgica para disminuir la exposición del personal, se recomienda un máximo de cinco personas en sala. 
Tabla 1: Equipo de protección personal (EPP) obligatorio para atención de pacientes

COVID-19 del Centro Médico «Lic. Adolfo López Mateos».

\begin{tabular}{llll}
\hline Primera barrera de protección & \multicolumn{1}{c}{$\begin{array}{c}\text { Segunda barrera de } \\
\text { protección }\end{array}$} & \multicolumn{1}{c}{$\begin{array}{c}\text { Tercera barrera de } \\
\text { protección }\end{array}$} & $\begin{array}{c}\text { Cuarta barrera de } \\
\text { protección }\end{array}$ \\
\hline $\begin{array}{l}\text { 1. Uniforme textil o desechable } \\
\text { (filipina y pantalón quirúrgico) }\end{array}$ & $\begin{array}{l}\text { 1. Traje Tyvek } \\
\text { 2. Cubrebocas N95/KN95/P100 } \\
\text { 2. Gorro }\end{array}$ & $\begin{array}{l}\text { 1. Bata estéril desechable } \\
\text { 2. Tercer par de guantes } \\
\text { (quirúrgico) }\end{array}$ & $\begin{array}{l}\text { 1. Bata estéril textil } \\
\text { 2. Cuarto par de guantes } \\
\text { (quirúrgico) }\end{array}$ \\
4. Segundo gorro & & \\
4. Primer par de guantes & 5. Segundo par de guantes & & \\
\hline
\end{tabular}

\section{Personal médico}

El equipo quirúrgico está formado por personal de adscritos con experiencia (dos cirujanos maxilofaciales, anestesiólogo y personal de enfermería quirúrgica) con el fin de minimizar los tiempos operativos y reducir el riesgo de contaminación. Todo el personal cuenta con las barreras de protección estandarizadas con base en protocolos internos, el equipo de protección personal incluye: gorro quirúrgico, lentes de protección, careta, cubrebocas N95 o mascarillas con filtros P100, uniforme quirúrgico desechable, traje Tyvek, bata de tela estéril, bata desechable estéril, guantes quirúrgicos y botas quirúrgicas, es importante mencionar que se debe evitar cualquier objeto fuera de las barreras como relojes, aretes, joyas, dispositivos electrónicos como celulares o cámaras (Tabla 1).

\section{Preparación de quirófano}

Previamente al ingreso del paciente a la sala asignada exclusiva para atención a pacientes positivos o con sospecha de COVID-19, el equipo quirúrgico inicia la colocación del equipo de protección personal (Tabla 1), anestesiología prepara todo lo necesario, se inicia la apertura de campo quirúrgico con técnica estéril, una vez que se tiene preparación de equipo quirúrgico, anestesiología y enfermería, se solicita por medio de enfermera circulante externa se baje paciente de hospitalización a dicha sala de quirófano, el paciente es trasladado con apoyo de ventilador mecánico de traslado evitando el uso de bolsa válvula mascarilla, todo el traslado se realiza con cercos clorados, posteriormente el paciente es ingresado en misma camilla de traslado hasta sala de quirófano evitando su movilización, se cierran las puertas de la sala (Tabla 2).
Dentro de la preparación del instrumental es importante mencionar que la cánula de traqueostomía debe ser cánula Shiley ${ }^{\mathrm{TM}}$ (Medtronic, Estados Unidos) o Portex ${ }^{\circledR}$ Blue Line Ultra ${ }^{\circledR}$ (Smiths Group plc, Reino Unido), siempre se deberá comprobar la integridad del globo. El diámetro de la cánula deberá ser solicitado de acuerdo con las características propias de cada paciente; sin embargo, se recomiendan diámetros menores evitando estomas amplios.

\section{Preparación de la anestesia}

Se prepara la sala antes del procedimiento y se cargan los medicamentos que se utilizarán para tenerlos disponibles. Se mantiene en posición supina, se puede realizar de forma empírica pinzamiento del tubo endotraqueal por arriba de la arcada dental para evitar el retorno de flujo residual del pulmón y pinzamiento del tubo del ventilador de traslado para evitar flujo de partículas provenientes del ventilador del traslado al ambiente y conectarlo a la máquina anestésica y viceversa, posteriormente se programa el ventilador mecánico al inicio del soporte ventilatorio, acorde a las necesidades del paciente como se muestra en la Tabla 3. ${ }^{14,17}$ Se procede a realizar inducción anestésica mediante anestésicos intravenosos y se mantiene con halogenados, los gases halogenados que van hacia el paciente con vía aérea artificial y requerimiento de ventilación mecánica, y los que salen de él hacia el ambiente siempre deberían ser filtrados. La remoción de partículas se puede lograr mediante diferentes mecanismos de acción con filtros tanto mecánicos como electrostáticos. Todas las partículas que miden menos de 10 micrómetros $(\mu \mathrm{m})$ de diámetro (1 $\mu \mathrm{m}=0.001$ milímetros) tienen el potencial de ser biológicamente activas en individuos susceptibles desde el punto de vista toxicológico. La mayoría 
Rev Mex Cir Bucal Maxilofac 2020;16 (2 y 3): 51-60

Tabla 2: Protocolo de colocación de EPP por el Centro Médico «Lic. Adolfo López Mateos».

Protocolo de colocación del equipo de protección personal (EPP)

1. Dentro del área gris del quirófano se coloca la primera barrera de protección, sin artículos personales (realizar exhaustivo lavado de manos)

2. Se coloca cubrebocas con la jareta inferior por debajo del pabellón auricular y la superior sobre la coronilla y que las jaretas no se crucen entre sí

3. Se coloca uniforme traje Tyvek y segundo par de guantes, aquí se puede agregar un segundo par de botas (segunda barrera)

4. Se colocan gafas protectoras quedando entre las dos jaretas del cubrebocas

5. Se coloca segundo gorro encima de las jaretas, colocación de gorro de Tyvek y careta encima del mismo

6. Comprobación de colocación de barreras iniciales previo a ingreso a área blanca

7. Se coloca primera bata estéril, ésta desechable y tercer par de guantes siguiendo una técnica estéril (tercera barrera)

8. Colocación de última barrera con bata textil estéril y último par de guantes

9. Aviso a personal externo de enfermería para solicitar ingreso de paciente a sala (no ingresar paciente sin que todo el personal cumpla con las barreras)

de las partículas con menos de $8 \mu \mathrm{m}$ de diámetro podrían impactar por encima del nivel de la laringe sin alcanzar el nivel pulmonar. Partículas en un rango de 1 a $8 \mu \mathrm{m}$ de diámetro podrían depositarse en las vías aéreas mayores y pequeñas y también en el alvéolo. ${ }^{17} \mathrm{El}$ rango de tamaño de partícula que alcanza mayor depósito alveolar se encuentra entre 1 y $2 \mu \mathrm{m}$ de diámetro. Un filtro comúnmente está compuesto de una estructura externa rígida que en su interior posee una lámina formada por fibras. Las partículas son capturadas por el mate-

Tabla 3: Programación básica del ventilador mecánico.

Modo ventilatorio
AC o SIMV
Espontánea
Volumen o presión
$\mathrm{FiO}_{2}$
Graduar con pulsioximetría
Objetivo llevar a 92\% o más
Meta menos de 50\%
Frecuencia respiratoria
12 a 16 rpm
Flujo pico, tiempo inspiratorio y relación I:E
Controla cuán rápido el VT es entregado o cuánto tiem-
po se aplica la presión inspiratoria programada
Normal $30-50$ lpm
Patrón de flujo
Cuadrada, desacelerada, sinusoidal

$\mathrm{AC}=$ asistida controlada, SIMV = ventilación obligatoria intermitente sincronizada, $\mathrm{FiO}_{2}=$ fracción inspirada de oxígeno, $\mathrm{rpm}=$ respiraciones por minuto, $\mathrm{VT}=$ volumen tidal, $\mathrm{I}=$ inspiratorio, $\mathrm{E}=$ espiratorio, Ipm = litros por minuto. Modificado de: Gutiérrez Muñoz F.16 rial que compone el filtro cuando el gas fluye a través del camino tortuoso creado por los espacios huecos interconectados dentro de la estructura del filtro. Es decir, a medida que el gas se mueve a través del filtro, las partículas se van depositando sobre el material. ${ }^{18}$ En forma simultánea se realiza antisepsia de región cervical y colocación de campos estériles, por parte de anestesiología se procede a hiperoxigenación hasta lograr la máxima saturación de oxígeno posible.

\section{Procedimiento quirúrgico}

Se continúa con infiltración de anestesia local en región pretraqueal con lidocaína y epinefrina al $0.2 \%$ con fines hemostáticos, esperamos cinco minutos para tener el efecto deseado, se ubica punto de incisión de $2 \mathrm{~cm}$ por arriba de manubrio esternal, se hace incisión horizontal de $3 \mathrm{~cm}$ respetando límites de triángulo de Jackson, se realiza disección roma con tijera Metzenbaum en sentido vertical y horizontal evitando sangrado y a su vez el uso de electrocauterio por la posible generación de gases, se continúa disección roma por planos hasta lograr exposición de anillos traqueales con control hemostático digital y con gasas, evitando el uso de aspiradores para no generar aerosoles, previo a la incisión en tejido traqueal se solicita al servicio de anestesiología la realización de preoxigenación al $100 \%$ por cinco minutos posteriormente, dejar apnea, esto para evitar el flujo de aire y secreciones, más tarde se desinfla el globo del tubo endotraqueal, y se debe desplazar distalmente a nivel de la carina, de manera que el globo quede fuera del área donde se hará el corte de la ventana traqueal para evitar romperlo. 
Tabla 4: Protocolo de retiro del EPP por el Centro Médico «Lic. Adolfo López Mateos». Siempre deberá ser supervisado por personal de enfermería capacitado y entre cada paso o maniobra manual se deberá realizar un exhaustivo lavado de manos.

Protocolo de retiro del equipo de protección personal

1. Enfermera circulante ayuda al equipo quirúrgico a desanudar las batas con desinfección de guantes antes y después de cada acción

2. Realizar retiro de la cuarta barrera de protección liberando la bata textil lentamente, tirando hacia el centro y frente, se envuelve de modo que la parte interna quede hacia afuera

3. Con ayuda de enfermera circulante y previa desinfección de guantes se libera la bata desechable hacia el centro y hacia el frente, removiendo el tercer par de guantes, de igual manera la parte interna queda hacia afuera

4. Desinfectar guantes internos con alcohol en gel y retirar careta tomándola de parte posterior con movimiento de atrás hacia adelante

5. Desinfectar los guantes internos con alcohol y gel y retirar el gorro de traje en un solo tiempo de adelante hacia atrás, enrollándolo en la parte de la nuca

6. Desinfectar guantes internos y retirar traje Tyvek junto con segundo par de guantes

7. Desinfectar guantes internos con alcohol gel, retirar segundo gorro y gafas protectoras de atrás hacia adelante en un solo tiempo

8. Desinfectar guantes internos con alcohol gel y retirar jareta superior del cubrebocas siguiendo por la jareta inferior

9. Desinfectar guantes internos con alcohol gel y retirar primer gorro

10. Desinfectar guantes internos con alcohol gel y retirar último par de guantes manipulando sólo lado interno de guante

11. Retiro de botas y pisar el primer cerco clorado haciendo un barrido de zapatos en cinco tiempos. Trasladarse al segundo cerco clorado y realizar de nuevo el barrido de zapatos

12. Realizar lavado de manos y trasladarse al área de vestidores, baño de regadera y cambio de ropa

13. Las enfermeras circulantes verifican adecuada y mutuamente el retiro y el adecuado depósito de los EPP

14. Ducharse en los vestidores

Se insufla nuevamente el globo del tubo endotraqueal en esta nueva posición para evitar el paso de secreciones hacia donde se realizará la ventana traqueal y se reanuda la ventilación del colgajo traqueal (Figura 2), posterior a la indicación de anestesiología se efectúa a nivel de cuarto anillo traqueal el colgajo de Björk, ${ }^{14}$ mismo que se fija a piel con sutura Nylon 3-0 (con la finalidad de encontrar rápidamente el estoma en caso de desalojo fortuito de la cánula de traqueostomía y sea de fácil acceso al mismo), se coloca cánula de traqueostomía, inflado de globo y conexión a circuito obteniendo buenos parámetros ventilatorios, por lo que se prosigue la fijación a las aletas a piel por medio de sutura nylon.

Los tratamientos quirúrgicos comparten características de preparación con un tiempo similar aproximado de 15 a 18 minutos. Una vez concluido el procedimiento quirúrgico el paciente es regresado a área de hospitalización con mismas medidas de traslado. ${ }^{14}$

La parte final del protocolo corresponde al retiro de todas las barreras de protección, esta parte es una de las que toman mayor relevancia debido al alto porcentaje de contagio del personal médico por la manipulación de materiales contaminados, por lo que deberá ser supervisado por un elemento específico del personal de enfermería (Tabla 4).

\section{Cuidados postoperatorios de traqueostomía (Tabla 5)}

\section{Pacientes con ventilación mecánica}

- Sin movilización del paciente por 24 horas. Este punto es muy importante, ya que se han presentado múltiples accidentes de desalojo de cánula de traqueostomía.

- Se debe utilizar un filtro viral en línea con el circuito del ventilador.

- Se deben usar succiones cerradas en línea y con filtro viral.

- Las cánulas internas desechables deben eliminarse y reemplazarse según las pautas del fabricante.

- No deben limpiarse ni reemplazarse.

\section{Pacientes sin ventilación mecánica}

- Incluso después del destete del ventilador, debe usarse un sistema cerrado, como un dispositivo de intercambio de calor y humedad con un filtro viral, para minimizar las secreciones en aerosol.

- Debe evitarse el collar de traqueotomía, pero se recomienda suturar la cánula a piel para evitar desalojos.

- También debe evitarse la succión innecesaria y el lavado pulmonar. 
- El cambio del tubo de traqueostomía debe diferirse hasta que el paciente ya no sea infeccioso después de consulta con el epidemiólogo o infectólogo a cargo. $6,7,9,13,14,18$

\section{RESULTADOS}

Los dos cirujanos maxilofaciales adscritos y el anestesiólogo del equipo quirúrgico que han participado en las traqueostomías del estudio durante el periodo de mayo a junio de 2020 , no han presentado síntomas relacionados con COVID-19; sin embargo; siguen en monitoreo.

\section{DISCUSIÓN}

Para el cirujano maxilofacial es vital el adiestramiento para realizar traqueotomías, ya que en nuestra zona anatómica de atención se presentan diversas patologías que pueden comprometer la vía aérea, por lo cual es importante tener en cuenta predictores de riesgo de obstrucción respiratoria.

En el Centro Médico «Lic. Adolfo López Mateos» el Servicio de Cirugía Maxilofacial se realizan traqueostomías que implican afecciones maxilofaciales, siendo de las más comunes las infecciones cervicofaciales; sin embargo, también son solicitadas por otros servicios como neurocirugía, medicina interna y unidad de cuidados intensivos que cuentan con pacientes con afecciones propias de sus especialidades y que presentan intubación prolongada.
Por ende, en la actualidad nuestro servicio de cirugía maxilofacial está participando en la realización de traqueostomías en pacientes con COVID-19 confirmado, es por ello que nos vimos en la necesidad de crear un protocolo de atención. La importancia de este artículo está relacionada con los cambios necesarios en los protocolos (como la apnea previa al cambio de sistemas de ventilación, introducir el tubo endotraqueal para poder hacer la traqueostomía sobre el tubo, mantener al paciente en apnea mientras se hace la incisión en la tráquea, no usar aspiradores ni electrobisturí en la traqueostomía, hacer disección roma para la exposición de la tráquea, usar todas las medidas de protección antes mencionadas, poner mayor atención al retiro adecuado del equipo de protección, ya que es ahí cuando se puede presentar mayor riesgo de contaminación y por último ducharse después de retirar el EPP), y guías terapéuticas en pacientes sin COVID-19 y que serán sometidos a traqueostomías y el riesgo del personal de salud del manejo de la vía aérea en pacientes COVID-19, o tan sólo el hecho de haber pacientes que se desconocen como positivos y se encuentran asintomáticos. ${ }^{14,19}$

La importancia de este virus es su alto grado de contagio y entender la relevancia de utilizar el equipo de protección personal y un proceso adecuado del manejo de pacientes en el quirófano debido a las partículas como gotas y aerosoles potencialmente infectantes para el personal de salud. Las gotas infectantes se encuentran en vía aérea del paciente y los aerosoles son partículas que miden menos de

Tabla 5: Protocolo sugerido para la realización de traqueostomías por el Servicio de Cirugía Maxilofacial del Centro Médico «Lic. Adolfo López Mateos».

Resumen de protocolo sugerido

1. Colocación de los EPP del equipo quirúrgico

2. Preparación de sala quirúrgica por parte del servicio de anestesiología, funcionamiento de máquina anestésica y disponibilidad de medicamentos

3. Apertura del instrumental quirúrgico, ingreso de paciente a sala con ventilador mecánico portátil, se comprueba vía periférica permeable y monitoreo

4. Establecimiento de parámetros ventilatorios, pinzamiento del tubo endotraqueal de ventilador portátil a circuito de máquina anestésica

5. Inducción anestésica intravenosa y mantenimiento con halogenados y corroboración de signos vitales estables

6. Infiltración de anestésico local periférico a la tráquea

7. Ubicación de punto de incisión y su posterior realización disección por planos

8. Exposición de anillos traqueales

9. Solicitar al servicio de anestesiología realización de apnea con desplazamiento de globo a nivel de la carina

10. Realización de colgajo de Björk y colocación de cánula con fijación a piel

11. Conexión a circuito ventilatorio con corroboración ventilatoria clínica y con parámetros 

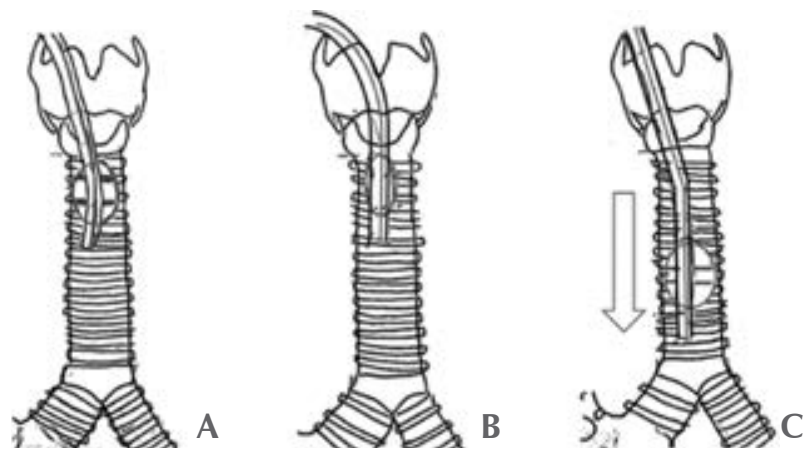

Figura 2: A) Posición habitual adecuada del globo. B) Desinflado de globo para una posterior colocación más distal a nivel de la carina. C) Inflado del globo por debajo de la localización del lugar de incisión.

10 micras que al ser livianas quedan suspendidas en el medio ambiente, son capaces de desplazarse a grandes distancias y al ser inhaladas se alojan a nivel alveolar. ${ }^{1}$

Por ello, el personal de salud debe asegurarse de contar con lo necesario para su protección personal como las mascarillas N95 o P100, sumado al equipo y procedimientos descritos en este artículo, dando mayor importancia al retiro del EPP para minimizar contacto con gotas o aerosoles en quirófano al abordar una traqueostomía debido a la exposición de la vía área del paciente. Para los cirujanos maxilofaciales el equipo de protección debe ser considerado en todo paciente de atención convencional, ya que sabiendo que las secreciones como saliva son de alto grado de contagio y sumado a esto el uso de rotatorios que genera gran cantidad de aerosoles.

En el quirófano debe haber una buena coordinación entre los integrantes del equipo, ya sea enfermeras, anestesiólogo y cirujano; los objetivos son disminuir los tiempos quirúrgicos, exposición y riesgo. De igual manera cada procedimiento, sea electivo o de urgencia, debe ser notificado y comunicado marcando las rutas del paciente, y el personal debe estar preparado y en espera del paciente en el quirófano.

Debido al riesgo de contraer el virus por fómites como los dispositivos electrónicos, el protocolo propuesto no permite el uso de los mismos, por lo que no se cuentan con imágenes dentro del quirófano.

En este centro médico se siguen las recomendaciones para realizar las traqueostomías posterior a los 21 días, ya que con base en las publicaciones, hasta el momento no hay ventajas significativas en una traqueostomía temprana ${ }^{14}$ con el propósito de disminuir el riesgo de exposición del personal de salud. Nuestro protocolo es la unión de sugerencias y protocolos propuestos por instituciones y/o asociaciones nacionales e internacionales, es un trabajo conjunto con personal de enfermería y otras áreas quirúrgicas.

Todas las recomendaciones tienen como objetivo común la seguridad del personal médico involucrado; sin embargo, se deben resaltar puntuaciones específicas, por ejemplo, la que menciona la Sociedad Canadiense de Otorrinolaringología que enfatiza no realizar una traqueostomía en pacientes con COVID19 con potencial infeccioso mayor por la inestabilidad sistémica.

Este procedimiento sólo debe considerarse si el tubo endotraqueal demuestra ser insuficiente para proporcionar una vía aérea adecuada. ${ }^{16} \mathrm{El}$ momento óptimo de la traqueostomía en pacientes críticos sigue siendo controvertido. Hiramatsu y colaboradores presentan informes anteriores de la pandemia de SARS, donde se mostró que el tiempo desde la intubación traqueal hasta la traqueotomía osciló entre 14 y 25 días. Si se considera inestable una condición general, se debe evitar la traqueotomía temprana (dentro de los 10 días) en estos nuevos pacientes con insuficiencia respiratoria aguda. ${ }^{18}$ Otras recomendaciones relacionadas con el procedimiento quirúrgico es mantener al paciente paralizado, preoxigenado, mantener la ventilación antes de que se haga una incisión en la tráquea para minimizar la aerosolización como lo menciona AO CMF. ${ }^{10}$

Actualmente la demanda de este procedimiento es mayor, puesto que gran porcentaje de la población ya se ha expuesto a este nuevo virus; de igual manera la cantidad de pacientes contagiados ha incrementado la necesidad de intubación prolongada y la progresión ventilatoria posterior requiere este procedimiento, por lo que deberán efectuarse estudios que correlacionen los contagios en el personal de salud encargado de realizar traqueostomías y evalúen la eficacia del protocolo propuesto. En publicaciones futuras presentaremos los resultados en caso de contagios en nuestro personal y la evolución de nuestros pacientes.

\section{CONCLUSIONES}

Nos estamos enfrentando a una enfermedad nueva que está afectando a muchos países, el conocimiento en relación con la enfermedad se desarrolla día a día, con constantes actualizaciones y cambios importantes en distintas publicaciones científicas reportadas 
en distintas plataformas de las diferentes especialidades médicas en todo aspecto de la enfermedad: en su comportamiento, fisiopatología, métodos diagnósticos, tratamiento farmacológico, rehabilitación y procedimientos quirúrgicos. Es por ello que debemos estar muy atentos, y los protocolos se deben ir modificando de acuerdo al conocimiento que se tenga y evolución de la enfermedad. Esta técnica propuesta puede ayudar a eliminar la cantidad de aerosoles, por lo que se lograría reducir considerablemente el riesgo de contagio por COVID-19 del cirujano maxilofacial durante una traqueostomía.

\section{BIBLIOGRAFÍA}

1. Zhu N, Zhang D, Wang W, Li X, Yang B, Song J et al. A novel coronavirus from patients with pneumonia in China, 2019. N Engl $\mathrm{J}$ Med. 2020; 382 (8): 727-733.

2. Zhao Z, Gao D. Precaution of 2019 novel coronavirus infection in department of oral and maxillofacial surgery. $\mathrm{Br} \mathrm{J}$ Oral Maxillofac Surg. 2020; 58 (3): 250-253.

3. Foster P, Cheung T, Craft P, Baran K, Kryskow M, Knowles R et al. Novel approach to reduce transmission of COVID-19 during tracheostomy. J Am Coll Surg. 2020; 230 (6): 1102-1104.

4. Coronavirus [Internet]. Who.int. 2020 [cited 17 Jun 2020]. Available from: https://www.who.int/emergencies/diseases/ novel-coronavirus-2019?gclid=CjwKCAjwte71BRBCEiwAU_ V9hwztErpXyutsyTE9Q6wbFB5xmEk7vCit12ywx67qTSHHc CFZEUrXZRoCIYMQAvD_BwE.

5. Lineamiento estandarizado para la vigilancia epidemiológica y por laboratorio de enfermedad por 2019-nCoV. Secretaría de Salud. Subsecretaría de Prevención y Promoción de la Salud. Dirección General de Epidemiología. 7 de febrero 2020. [Fecha de acceso 17 de junio 2020] Disponible en: https://www.gob.mx/cms/uploads/ attachment/file/533167/Lineamiento_2019_nCoV_2020_02_07.pdf

6. Takhar A, Walker A, Tricklebank S, Wyncoll D, Hart N, Jacob T et al. Recommendation of a practical guideline for safe tracheostomy during the COVID-19 pandemic. Eur Arch Otorhinolaryngol. 2020; 277 (8): 2173-2184.

7. Saavedra-Mendoza AGM, Akaki-Caballero M y col. Traqueotomía en pacientes con COVID-19: recomendaciones de la Sociedad Mexicana de Otorrinolaringología y Cirugía de Cabeza y Cuello. Cuándo y cómo realizarla y cuidados posquirúrgicos. An Orl Mex. 2020; 65: 1-11.
8. Atkinson J, Chartier Y, Pessoa-Silva CL et al. Natural ventilation for infection control in health-care settings. Geneva: World Health Organization; 2009. Annex C, Respiratory droplets. Available from: https://www.ncbi.nlm.nih.gov/books/NBK143281/.

9. Haspel AC, Coviello VF, Stevens M. Retrospective study of tracheostomy indications and perioperative complications on oral and maxillofacial surgery service. J Oral Maxillofac Surg. 2012; 70 (4): 890-895.

10. Arbeitsgemeinschaft für Osteosynthesefragen Craniomaxillofacial: AO CMF International Task Force Recommendations on Best Practices for Maxillofacial Procedures during COVID-19 Pandemic. Available in: https://www. aofoundation.org/what-we-do/covid19-resources-for-surgeons\#COVIDnews_0=News\%20Date\%20 Facet,Descending

11. Hosokawa K, Nishimura M, Egi M, Vincent JL. Timing of tracheotomy in ICU patients: a systematic review of randomized controlled trials. Crit Care. 2015; 19: 424.

12. Chao TN, Braslow BM, Martin ND, Chalian AA, Atkins J, Haas AR et al. Tracheotomy in ventilated patients with COVID-19. Ann Surg. 2020; 272 (1): e30-e32.

13. Givi B, Schiff BA, Chinn SB, Clayburgh D, lyer NG, Jalisi S et al. Safety recommendations for evaluation and surgery of the head and neck during the COVID-19 pandemic. JAMA Otolaryngol Head Neck Surg. 2020; 146 (6): 579-584.

14. Tracheotomy Recommendations During the COVID-19 Pandemic [Internet]. American Academy of Otolaryngology-Head and Neck Surgery. 2020 [cited 15 May 2020]. Available from: https://www. entnet.org/content/tracheotomy-recommendations-during-covid19-pandemic

15. Hiramatsu M, Nishio N, Ozaki M, Shindo Y, Suzuki K, Yamamoto $T$ et al. Anesthetic and surgical management of tracheostomy in a patient with COVID-19. Auris Nasus Larynx. 2020; 47 (3): $472-$ 476.

16. Sommer DD, Engels PT, Weitzel EK, Khalili S, Corsten M, Tewfik $\mathrm{MA}$ et al. Recommendations from the CSO-HNS taskforce on performance of tracheotomy during the COVID-19 pandemic. J Otolaryngol Head Neck Surg. 2020; 49 (1): 23.

17. Fredes S, Gogniat E, Plotnikow G, Rodrigues-La Moglie R. Utilización de filtros bacterianos/virales durante la ventilación mecánica invasiva. Med Intensiva. 2013; 30 (1).

18. Gutiérrez Muñoz F. Ventilación mecánica. Acta Med Peruana. 2011; 28 (2): 87-104.

19. Shiba T, Ghazizadeh S, Chhetri D, St John M, Long J. Tracheostomy considerations during the COVID-19 pandemic. OTO Open. 2020; 4 (2): 2473974X20922528.

Conflicto de intereses: No hay conflicto de intereses. 